Н. Т. Юшкевич ${ }^{1}$ Ю. И. Шумский르, А. В. Неверов ${ }^{1}$, А. В. Рубис ${ }^{1}$

${ }^{1}$ Белорусский государственный технологический университет ${ }^{2}$ РГОО «Белорусское общество охотников и рыболовов»

\title{
ЦИФРОВАЯ ТРАНСФОРМАЦИЯ КАК МЕХАНИЗМ РАЦИОНАЛЬНОГО ИСПОЛЬЗОВАНИЯ ЛЕСНЫХ И ОХОТНИЧЬИХ РЕСУРСОВ
}

Для максимально эффективного использования новых технологий и их оперативного внедрения во все сферы деятельности человека предприятия должны отказаться от прежних устоев и полностью преобразовать процессы и модели работы. Это означает постепенный отказ от устаревших технологий, обслуживание которых может дорого обходиться предприятиям.

В лесном секторе нашей страны цифровая трансформация впервые серьезно начала внедряться еще в конце 90-х гг. прошлого столетия, когда была создана информационная система управления лесным хозяйством (ИСУЛХ). Она создана как многоуровневая, интегральная, многоцелевая система управления лесами, лесным хозяйством и лесными ресурсами. В мае 2017 г. принято решение о разработке и внедрении в промышленную эксплуатацию Единой государственной автоматизированной информационной системы учета древесины и сделок с ней (ЕГАИС). Данная система позволяет предъявлять единые требования к учету древесины, контролировать все этапы движения древесины в заготовленном виде, используя информацию только в электронном виде.

В охотничьей хозяйственной деятельности нашей страны информационные технологии позволяют оплачивать рыболовные и охотничьи взносы РГОО «БООР», приобретать охотничьи путевки без предварительного посещения охотхозяйства, дистанционно через геоинформационные системы (загружены актуальные карты-схемы охотничьих угодий всех охотничьих хозяйств) знакомиться с местом охоты и др.

Таким образом, процесс внедрения современных цифровых технологий означает постепенный отказ от устаревших технологий, повышение эколого-экономической эффективности использования лесных и охотничьих ресурсов, а также изменение культуры, которая теперь должна поддерживать ускорение процессов, обеспечиваемое цифровой трансформацией.

Ключевые слова: цифровая трансформация, эффективность, рациональное использование, устойчивое управление.

Для цитирования: Юшкевич Н. Т., Шумский Ю. И., Неверов А. В., Рубис А. В. Цифровая трансформция как механизм рационального использования лесных и охотничьих ресурсов // Труды БГТУ. Сер. 1, Лесное хоз-во, природопользование и перераб. возобновляемых ресурсов. 2021. № 1 (240). С. 101-106.

\author{
N. T. Yushkevich ${ }^{1}$, Yu. I. Shumski ${ }^{2}$, A. V. Neverov ${ }^{1}$, A. V. Rubis ${ }^{1}$ \\ ${ }^{1}$ Belarusian State Technological University \\ ${ }^{2}$ RSOO "Belarusian Society of Hunters and Fisherman"
}

\section{DIGITAL TRANSFORMATION AS A MECHANISM FOR RATIONAL USE OF FOREST AND HUNTING RESOURCES}

Enterprises must abandon the previous foundations and completely transform processes and work models for the most effective use of new technologies and their prompt implementation in all areas of human. This process means phasing out obsolete technologies that can be expensive for businesses to maintain.

Digital transformation in the forestry sector of our country for the first time seriously began to be introduced back in the late 90 s of the last century, when the forestry management information system (FMIS) was created.It was created as a multi-level, integrated, multi-purpose forest management system, forestry and forest resources. In May 2017, a decision was made to develop and introduce into industrial operation a unified state automated information system for accounting for timber and transactions with it (USAIS). This system will make it possible to present uniform requirements for timber accounting, control all stages of the movement of timber in the harvested form, using information only in electronic form.

In the hunting economic activity of our country, information technology allows you to pay fishing and hunting fees of the Republican state-public association "Belarusian society of hunters and fishermen". 
There is a possibility of purchasing hunting permits without first visiting a hunting farm, you can remotely through geoinformation systems (up-to-date maps-schemes of hunting grounds of all hunting farms are loaded) to get acquainted with the hunting area, etc.

Thus, the process of introducing modern digital technologies means a gradual abandonment of outdated technologies, an increase in the environmental and economic efficiency of the use of forest and hunting resources, as well as a change in culture, which should now support the acceleration of processes provided by digital transformation.

Key words: digital transformation, efficiency, rational use, sustainable management.

For citation: Yushkevich N. T., Shumski Yu. I., Neverov A. V., Rubis A. V. Digital transformation as a mechanism for rational use of forest and hunting resources. Proceedings of BSTU, issue 1, Forestry. Nature Management. Processing of Renewable Resources, 2021, no. 1 (240), pp. 101-106 (In Russian).

Введение. Цифровая трансформация - это процесс интеграции цифровых технологий во все аспекты бизнес-деятельности, требующий внесения коренных изменений в технологии, культуру, операции и принципы создания новых продуктов и услуг. Для максимально эффективного использования новых технологий и их оперативного внедрения во все сферы деятельности человека предприятия должны отказаться от прежних устоев и полностью преобразовать процессы и модели работы. Цифровая трансформация требует смещения акцента на периферию предприятий и повышение гибкости центров обработки данных, которые должны поддерживать периферию. Этот процесс также означает постепенный отказ от устаревших технологий, обслуживание которых может дорого обходиться предприятиям, а также изменение культуры, которая теперь должна поддерживать ускорение процессов, обеспечиваемое цифровой трансформацией.

Когда предприятия осознали все возможности использования оцифрованных данных, они стали разрабатывать процессы для этих целей. С этого момента цифровые технологии начали бурно развиваться, и способность быстро внедрять их напрямую определяет конкурентоспособность предприятий. И хотя цифровая трансформация сейчас является популярной темой обсуждений среди технических специалистов, на самом деле о ней говорят уже несколько десятилетий. Однако этот термин не всегда означал одно и то же. Долгое время под ним подразумевался перевод в цифровой формат или хранение в цифровом виде традиционных форм данных. Это тоже одно из направлений цифровой трансформации, однако в современном мире данное понятие гораздо шире, чем перевод в цифровой формат.

Очень часто трансформация происходит не потому, что предприятия так решают, а потому, что это им необходимо, чтобы выжить. Сегодня на рынке вырос спрос на эффективные цифровые технологии для бизнеса, и предприятия, которые не смогли адаптироваться к новой модели цифрового потребителя, наверняка прекратят свое существование.

Вопросы цифровой трансформации и информационных технологий рассматриваются в работах Л. И. Алешина [1], С. Аракеляна [2], М. А. Венделева [3], О. Н. Граничина [4] и др. $[5,6]$.

Предприятия, которые приветствуют перемены и готовы к ним, а также способны адаптироваться к более гибким моделям работы, имеют как никогда большой потенциал успеха. Это связано с тем, что цифровая трансформация охватывает все аспекты бизнеса и предлагает эффективные пути их совершенствования вместе с развитием цифровых технологий.

Этапы цифровой трансформации:

- создание плана, в котором учтены все бизнес-потребности предприятия;

- обучение сотрудников навыкам работы с новыми технологиями;

- отказ от устаревших технологий.

Основная часть. В лесном секторе нашей страны цифровая трансформация впервые серьезно начала внедряться еще в конце $90-$ х гг. прошлого столетия благодаря «Проекту развития лесного хозяйства», финансируемому Мировым банком реконструкции и развития. Под руководством профессора БГТУ Атрощенко О. А. впервые была создана в Министерстве лесного хозяйства информационная система управления лесным хозяйством (ИСУЛХ). Она разрабатывалась как многоуровневая, интегральная, многоцелевая система управления лесами, лесным хозяйством и лесными ресурсами.

В первую очередь это система функционирует в лесхозах по лесохозяйственной деятельности, например автоматизированное рабочее место (АРМ) «Лесопользование», система планирования лесного кадастра, ГИС-технологии и система АРМ лесов.

Система устойчивого управления лесами Беларуси основана на европейских принципах и соглашениях, критериях и показателях национальной системы лесной сертификации [7]. 
Устойчивое управление лесами - это устойчивое лесовосстановление, лесовозобновление и лесопользованние, защита и охрана лесов таким образом, чтобы леса и лесные ресурсы выполняли в настоящем и будущем экологические, экономические и социальные функции [8].

ИСУЛХ состоит из трех систем:

1) система сбора и обработки информации;

2) система планирования и разработки альтернативных вариантов устойчивого управления лесами и лесными ресурсами;

3) система принятия решения с выбором оптимальных значений для принятия поставленных целей:

- улучшение породной структуры лесов;

- выравнивание возрастной структуры;

- оптимизация лесопользования;

- достижения максимальных доходов;

- сохранение средообразующей функции лесов.

Вместе с тем для достижения любой из этих целей лесоуправления необходимо дополнительно разработать целевую функцию, критерий, модель оптимизации и решать задачи с применением методов математического программирования.

В мае 2017 г. Главой государства принято решение о разработке и внедрении в промышленную эксплуатацию Единой государственной автоматизированной информационной системы учета древесины и сделок с ней (ЕГАИС).

Данная система позволит предъявлять единые требования к учету древесины как на землях лесного фонда, так и на землях, не входящих в состав лесного фонда, контролировать все этапы движения древесины в заготовленном виде, используя информацию только на электронных носителях.

Это позволит модернизировать технологии по учету при вывозке и реализации древесины в процессе осуществления хозяйственной и иной деятельности, рационального использования лесов, а также обеспечения экономических интересов государства в области лесопользования и при удалении объектов растительного мира при проведении работ на землях, не входящих в состав лесного фонда.

В Российской Федерации аналогичная Государственная автоматизированная информационная система учета древесины «ЕГАИС Лес» была создана в 2014 г. для контроля происхождения и оборота древесины. Система проводит учет древесины в стране и контролирует любые сделки с ней, а также проверяет правомерность таких сделок с точки зрения законодательства РФ. Она полностью контролирует весь процесс, начиная с вырубки деревьев и заканчивая продажей древесины конечному пользователю.

Каждый этап подтверждается документально, а потом регистрируется в виде электронного документа в ЕГАИС Лес. Данный программный продукт регистрирует сделки не только внутри страны, но и импорт-экспорт древесины. В соответствии с законодательством РФ использование системы субъектами хозяйствования, осуществляющими деятельность в области лесопользования, является обязательным условием для участников рынка и распространяется на все сделки с древесиной и лесопродукцией.

Согласно законодательству Российской Федерации, все заготовщики, экспортеры, импортеры и внутренние продавцы и покупатели древесины, в том числе и пиломатериалов, обязаны всю деятельность осуществлять через ЕГАИС. Они должны сдавать в систему отчеты о вырубке, изменении размеров участков, продаже, покупках и переработке, а также декларацию о транспортировке.

Цели внедрения ЕГАИС Лес носят комплексный, межведомственный характер и направлены на противодействие незаконным рубкам, усиление контроля за оборотом древесины, вследствие которого отслеживается вся цепочка лесопользования: от заготовки до поставки леса потребителям. Данная система является реально действующим механизмом в борьбе с «черными лесорубами» и теневым бизнесом. Схожие системы имеются также в Украине, государствах Балтии, Польше, Скандинавии, Финляндии и других странах с высокоразвитым лесным хозяйством.

В Республике Беларусь ЕГАИС разрабатывается впервые. Отечественных аналогов такой системы не существует. В ЕГАИС предполагается использование современных информационных технологий с учетом передового отечественного и зарубежного опыта, в том числе технологий единой базы данных для доступа к ней как с мобильных устройств, так и стационарных рабочих мест, технологий современных сетей передачи данных, технологий генерации отчетных документов по учету древесины.

Посредством системы будет осуществляться информационная поддержка и комплексная автоматизация процессов, связанных с выполнением первичных регистрационно-учетных операций и предоставлением данных об объемax заготовки древесины, а также перемещении лесоматериалов.

Система по виду автоматизируемой деятельности относится к системам оперативной обработки данных, которые обеспечивают функции их сбора, контроля, регистрации, хранения, обработки и передачи. 
Создание ЕГАИС позволит решить такие задачи:

- создать базу данных об учете сделок с древесиной, объемах древесины, передаваемой от одних хозяйствующих субъектов другим;

- обеспечить эффективный контроль и прозрачность информации о движении и наличии древесины;

- оптимизировать и минимизировать ручной труд и ошибки, связанные с человеческим фактором;

- сократить время и средства при учете заготовки, вывозки и реализации лесоматериалов;

- разработать механизм обеспечения управленческого персонала оперативной и достоверной информацией для планирования процессов заготовки и отгрузки древесины;

- внедрить управление движением ресурсов в цепи поставок на основе научно обоснованных логистических схем.

Создание системы позволит контролировать все этапы заготовки древесины и ее движения (не только от заготовки в лесном фонде до приемки у потребителя, но и на землях, не входящих в состав лесного фонда), используя при этом информацию только в электронном виде, и обеспечить рациональное использование лесных ресурсов за счет совершенствования управления и снижения трудозатрат.

Социальная эффективность внедрения ЕГАИС будет определяться сокращением трудозатрат на выполнение трудоемких функций.

Использование системы:

- повысит точность, качество и оперативность информационного обеспечения при решении задач по учету и реализации древесины, ее рациональному использованию;

- позволит использовать единое информационное пространство для сбора, обработки, хранения и предоставления актуальной информации, необходимой для ведения лесного хозяйства - данных о местах и объемах заготовки древесины, ее количестве, качестве, перемещении, о лицах и лесозаготовительных машинах, участвующих в процессе заготовки древесины;

- обеспечит прозрачность информации о движении и наличии древесины и эффективный контроль над оперативной деятельностью;

- даст возможность оптимизировать и минимизировать ручной труд и ошибки, связанные с человеческим фактором.

Экономическая эффективность реализации мероприятия определяется:

- получением прибыли оператором ЕГАИС за ее регистрацию юридическим лицам, ведущим лесное хозяйство, лесозаготовительным организациям, перевозчикам, потребителям древесины и контролирующим органам, а также получением прибыли за сопровождение;

- сокращением времени и средств по учету древесины при ее заготовке, вывозке и реализации.

В целом по лесохозяйственной отрасли при практическом применении ЕГАИС ожидается экономический эффект ориентировочно до 4,4 млн. руб. в год.

В охотничьей хозяйственной деятельности нашей страны информационные технологии серьезно начали внедряться особенно в последнее десятилетие. Так, в настоящее время охотники и рыболовы - члены республиканской государственно-общественной организации «Белорусское общество охотников и рыболовов» (РГОО «БООР») могут воспользоваться ниже перечисленными современными технологиями.

Теперь не только рыболовные, но и охотничьи взносы РГОО «БООР» можно оплачивать с использованием Единого расчетного и информационного пространства (ЕРИП). При этом произвести оплату можно как с помощью персонального компьютера, так и со смартфона.

Для удобства охотников в охотхозяйствах системы РГОО «БООР» существует возможность приобретения охотничьих путевок без предварительного посещения охотхозяйства они приобретаются в электронном виде на сайте ihunt.by. Для этого необходимо зарегистрироваться на сайте и оплатить через ЕРИП охотничью путевку.

Для ознакомления с местом охоты на сайте rgooboor.by загружены актуальные картысхемы охотничьих угодий всех охотничьих хозяйств РГОО «БООР». Причем качество изображения позволяет в деталях изучить интересующие места охоты.

Также на сайте rgooboor.by существует база данных охотничьих собак, зарегистрированных в РГОО «БООР». В этой базе данных пользователи могут ознакомиться со следующей информацией: узнать кличку, породу охотничьей собаки, номер ее родословной, номер регистрационной карточки, номер клейма (чипа), увидеть фото собаки. Благодаря этой базе данных у пользователей есть возможность идентифицировать найденную охотничью собаку или подобрать кандидатуру для вязки.

Если возникнет необходимость устроиться на ночлег, для удобства поиска подходящих вариантов все дома охотника и рыболова РГОО «БООР» внесены в базу популярного сервиса booking.com. 
Заключение. Таким образом, процесс внедрения современных цифровых технологий также означает постепенный отказ от устаревших технологий, обслуживание которых может дорого обходиться организациям лесного и охотничьего хозяйства, а также изменение культуры, которая теперь должна поддерживать ускорение процессов, обеспечиваемое цифровой трансформацией. Цифровая трансформация соответствует социально-экономическим потребностям и возможностям общества и государства, целям устойчивого развития.

\section{Список литературы}

1. Алешин Л. И. Информационные технологии: учеб. пособие. М.: Маркет ДС, 2011. 384 с.

2. Аракелян С. Цифровая экономика: стратегии развития и новые технологии - достижения, риски, угрозы // Экономист. 2018. № 3. С. 52-73.

3. Венделева М. А., Вертакова Ю. В. Информационные технологии в управлении: учеб. пособие. М.: Юрайт, 2013. 462 с.

4. Граничин О. Н., Кияев В. И. Информационные технологии в управлении: учеб. пособие. М.: БИНОМ. ЛЗ, ИНТУИТ, 2008. 336 с.

5. Савина Т. С. Цифровая экономика как новая парадигма развития: вызовы, возможности и перспективы // Финансы и кредит. 2018. № 10. С. 579-590.

6. Чалдаева Л. Цифровая экономика: вчера, сегодня и завтра // Экономист. 2018. № 4. C. $80-85$.

7. Зорин В. П. Теоретические основы лесной сертификации в системе устойчивого управления лесами // Труды БГТУ. Сер. 1, Лесное хозяйство: природопользование и переработка возобновляемых ресурсов. 2017. № 2. С. 165-169.

8. Неверов А. В., Водопьянов П. А. О модели устойчивого развития Республики Беларусь // Труды БГТУ. Сер. VII, Экономика и управление. 2007. Вып. XV. С. 7-14.

\section{References}

1. Aleshin L. I. Informatsionnyye tekhnologii: uchebnik [Information technology: textbook]. Moscow, Market DS Publ., 2011. 384 p.

2. Arakelyan S. Digital Economy: Development Strategies and New Technologies - Achievements, Risks, Threats. Ekonomist [The Economist], 2018, no. 3, pp. 52-73 (In Russian).

3. Vendeleva M. A., Vertakova Yu. V. Informatsionnyye tekhnologii v menedzhmente: uchebnik [Information technologies in management: textbook]. Moscow, Yurayt Publ., 2013. 462 p.

4. Granichin O. N., Kiyaev V. I. Informatsionnyye tekhnologii v menedzhmente: uchebnik [Information technologies in management: textbook]. Moscow, BINOM. LZ, INTUIT Publ., 2008. $336 \mathrm{p}$.

5. Savina T. S. Digital economy as a new development paradigm: challenges, opportunities and prospects. Finansy i kredit [Finance and Credit], 2018, no. 10, pp. 579-590 (In Russian).

6. Chaldaeva L. Digital economy: yesterday, today and tomorrow. Ekonomist [The Economist], 2018, no. 4, pp. 80-85 (In Russian).

7. Zorin V. P. Theoretical foundations of forest certification in the system of sustainable forest management. Trudy BGTU [Proceedings of BSTU], series 1, Forestry. Nature Management and Processing of Renewable Resources, 2017, no. 2, pp. 165-169 (In Russian).

8. Neverov A. V., Vodopyanov P. A. About the model of sustainable development of the Republic of Belarus. Trudy BGTU [Proceedings of BSTU], series 7, Economics and Management, 2007, issue 15, pp. 7-14 (In Russian).

\section{Информация об авторах}

Юшкевич Николай Тарасович - кандидат экономических наук, доцент кафедры туризма, природопользования и охотоведения. Белорусский государственный технологический университет (220006, г. Минск, ул. Свердлова, 13a, Республика Беларусь). E-mail: ushkevichn@tut.by

Шумский Юрий Иванович - председатель РГОО «Белорусское общество охотников и рыболовов» (220012, г. Минск, пер. Калинина, 16, Республика Беларусь). E-mail: rgooboor@mail.ru

Неверов Александр Васильевич - доктор экономических наук, профессор кафедры менеджмента, технологий бизнеса и устойчивого развития. Белорусский государственный технологический университет (220006, г. Минск, ул. Свердлова, 13a, Республика Беларусь). E-mail: neverov@belstu.by 
Рубис Александра Владимировна - магистрант. Белорусский государственный технологический университет (220006, г. Минск, ул. Свердлова, 13a, Республика Беларусь). E-mail: arubis1698@mail.ru

\section{Information about the authors}

Yushkevich Nikolay Tarasovich - PhD (Economics), Associate Professor, the Department of Tourism, Nature Management and Game Management. Belarusian State Technological University (13a, Sverdlova str., 220006, Minsk, Republic of Belarus).E-mail: ushkevichn@tut.by

Shumski Yury Ivanovitch - Chairman of the RSOO "Belarusian Society of Hunters and Fisherman" (16, Kalinin lane, 220012, Minsk, Republic of Belarus). E-mail: rgooboor@mail.ru

Neverov Aleksandr Vasil'yevich - DSc (Economics), Professor, the Department of Management, Business Technologies and Sustainable Development. Belarusian State Technological University (13a, Sverdlova str., 220006, Minsk, Republic of Belarus). E-mail: neverov@belstu.by

Rubis Alexandra Vladimirovna - Master's Degree. Belarusian State Technological University (13a, Sverdlova str., 220006, Minsk, Republic of Belarus). E-mail: arubis1698@mail.ru 